\title{
"We Pride Ourselves on Being Strong... and Able to Bear a lot": Examining the Socio-Cultural and Historical Context of Black Americans' Experiences with Depression and Help-Seeking
}

\author{
Rosalyn Denise Campbell
}

\begin{abstract}
Research consistently shows that Black Americans' symptoms of depression are more severe and persistent than their white counterparts yet they seek out and/or use services at a far lower rate. While trying to understand this disparity, it is important that researchers explore the socio-cultural and historical context around Black Americans' experiences with depression and help-seeking. This study involved semi-structured indepth interviews with 17 Black American men and women, aged 21-57, who experienced depression. A thematic analysis revealed that Black Americans' experiences are often rooted in a socio-cultural and historical context where Black people are seen as a strong people, able to deal with anything, and do not get depressed. These findings suggest that Black Americans may go through a process of reconciling being depressed with certain aspects of their cultural identity as they strive to better understand themselves, their illness, and options to help alleviate their symptoms. Researchers and practitioners alike should pay more attention to this complex process as they attempt to understand the illness experiences and help-seeking behaviors of Black Americans.
\end{abstract}

Keywords: Depression; Black Americans; experiences; culture; help-seeking

Depression is a major mental health issue that impacts the lives of many in the U. S. regardless of racial/ethnic background (Kessler, Berglund et al., 2005, Williams et al., 2007). While Black Americans have consistently been found to be less likely to meet the diagnostic criteria for major depressive disorder (MDD) than Whites (Kessler, Berglund et al., 2005; Kessler, Chiu, Demler, \& Walters, 2005; Williams et al., 2007), the course of MDD among Blacks tends to be more severe and persistent (Williams et al., 2007). Black Americans have higher rates of unmet needs related to this disorder than do Whites (Redmond, Galea, \& Delva, 2009; USDHHS, 1999, 2001). Most of the diagnosable cases of MDD among Black Americans go untreated and tend to have more impairing effects (Wang et al., 2005; Williams et al., 2007). In terms of professional help-seeking for depression and other mental health problems, research has shown that Black Americans utilize mental health services at a rate below that of Whites (Alegría, Chatterji et al., 2008; Keyes et al., 2008; Williams et al., 2007), even when they have insurance. Despite efforts through the Affordable Health Care Act to increase access to care and establish mental health parity, the overall gap in service use between Blacks and Whites is expected to persist (Alegria, Lin et al., 2012). This means that the group who experiences greater burden due to this illness receives the least professional help.

To better understand these disparities, it is important to take a closer look at the experiences of Black Americans with depression, including their experiences of the disorder itself as well as their help-seeking behaviors and service use patterns related to

Rosalyn Denise Campbell, PhD, LMSW is an Assistant Professor, School of Social Work, University of Georgia, Athens, GA 30605-1746.

Copyright @ 2017 Author, Vol. 18 No. 2 (Fall 2017), 663-681, DOI: 10.18060/21235

(cc) BY

This work is licensed under a Creative Commons Attribution 4.0 International License. 
this illness. Part of this exploration must include an examination of the socio-cultural and historical context of those experiences. This study sought to do just that by interviewing Black Americans diagnosed with depression about their experiences, focusing specifically on how various aspects of culture and history influence those experiences.

\section{Literature Review}

\section{Culture and Health}

To begin to understand the socio-cultural and historical context of Black Americans' experiences with depression, it is important that the impact of culture on health is explored. Culture, as it is used and understood in this study, is "broadly defined as a common heritage or set of beliefs, norms, and values" (USDHHS, 1999, 2001, p. 9). Research has shown that "culture plays a [crucial] role in shaping beliefs, value and rule systems, problemsolving patterns, communication styles, and learned coping behaviors" (Matthews \& Hughes, 2001, p. 77). Health behavior, or how people think about and define illness as well as how they think about and approach health and healing, is heavily shaped by culture (Angel \& Thoits, 1987; Bagley, Angel, Dilworth-Anderson, Liu, \& Schinke, 1995; Kleinman, 1980, 1992; Murray, 2001; Olafsdottir \& Pescosolido, 2009). Moreover, what is considered normal behavior and what is considered symptomatic of an illness is determined based on any given number of factors and/or circumstances, meaning culturally-shaped conceptions of "health" and "illness" can vary according to time, place, and social context (Angel \& Thoits, 1987; Capers, 1991; Kleinman, 1988; Murray, 2001; Scheff, 1966). Culture also influences how people experience illness and how their distress is communicated (Angel \& Thoits, 1987; Bagley, et al., 1995; Good, 1997; Kleinman, 1988; Murray, 2001).

While scholars, researchers, and practitioners know that culture has a strong influence on health, it has become a "long abandoned topic" in scholarship (Small, Harding, \& Lamont, 2010, p. 6). With the popularization and subsequent vilification by many of the "culture of poverty" doctrine introduced by Oscar Lewis in the 1960s, many scholars sought to distance themselves from a theory viewed as racist, ethnocentric, or at best, incomplete (Small et al., 2010, p. 6). However, rather than challenging the theory, many researchers abandoned culture as a crucial concept necessary for exploring differences between and within groups.

The use of the concept of culture in health research has its supporters and critics. As previously mentioned, because of the lingering legacy of the "culture of poverty" era, some interpret the use of "culture" in any type of commentary or analysis as a form of victimblaming (Small et al., 2010; Valentine, 1968). Critics of an (over)emphasis on culture, particularly in health research, believe that scarce resources should be used to research and craft interventions that can be applied more universally (Fabrega, 1989). On the other hand, those who support using culture in research and practice believe that it is an important lens to better view and understand health behavior (Angel \& Thoits, 1987; Bagley et al., 1995; Good, 1997; Kleinman, 1980, 1992; Murray, 2001; Olafsdottir \& Pescosolido, 2009). 
Arguably, most scholars believe that the problem with culture is not its inclusion in research but its misuse. A number of investigators have stated that the actual issue is the tendency of researchers to employ either outdated or narrow definitions of culture (Angel \& Thoits, 1987; Lopez \& Guarnaccia, 2000; Valentine, 1968). Too often particular beliefs, practices, and/or values are situated within a single ethnocultural group instead of viewed as expressions related to the beliefs and practices themselves, ones that the group just so happens to embody and employ (Lopez \& Guarnaccia, 2000). Therefore, some behaviors and norms are erroneously ascribed to a group that may not truly reflect its inner-workings. It is this practice that made the "culture of poverty" theory problematic (Valentine, 1968). Finally, some researchers over-emphasize differences between groups and underemphasize within group differences.

While the use of culture has had its problems in research, it still remains a key means to understanding how individuals from various racial/ethnic groups might think about depression and help-seeking, and thus, how they approach service use (Broman, 1987; Schnittker, Freese, \& Powell, 2000). An approach to research that acknowledges the influence of culture can offer a wealth of information to researchers and practitioners looking to better understand the health experiences, behaviors, and choices of people of color.

\section{Culture and Black Americans}

Black Americans have seen themselves historically, culturally, and socially as a strong people, and they have been viewed by others through both research and relationship as being resilient (Thompson, Bazile, \& Akbar, 2004; USDHHS, 2001). Surviving and overcoming historical injustices and experiences of discrimination have been the basis for feelings of cultural/racial pride, strength, and resolve. It is often this pride, along with the desire to handle problems themselves or with the help of loved ones that keeps a number of Black Americans from seeking professional help for mental health problems (Rostain, Ramsay, \& Waite, 2015). Further, depression is often seen as a sign of weakness (Alang, 2016), antithetical to the strength and resilience often associated with being Black. So what does this mean for a person whose racial group is seen socio-culturally and historically as strong? How do the feelings of weakness often associated with suffering from a mental disorder interact with the perception of strength linked with being a Black American? How, then, does this socio-cultural context influence and shape Black Americans' experiences with depression, help-seeking, and service use?

Only a small body of research has examined the direct link between cultural/racial identity and help-seeking among adults, particularly mental health service utilization. While the body of literature is small, it illuminates the importance of focusing on the sociocultural context of experiences, including meanings and messages around what it means to be Black and/or what help should look like when one is experiencing problems. For instance, Redmond and colleagues (2009) found that individuals reporting stronger cultural identity are more likely to view their experiences in treatment with some providers as less helpful and less fulfilling. 


\section{Specific Study Aims}

The original study, from which the basis of this manuscript was drawn, was aimed at better understanding the experiences of Black Americans with depression, including helpseeking behaviors and patterns of service use. The author used qualitative interviews to explore those experiences and a number of themes emerged. This analysis seeks to highlight those themes that spoke to the socio-cultural and historical context of those experiences. This study does not seek to extend blame or hold Black Americans responsible for the behaviors that are noted and the patterns that are observed herein; it simply attempts to better understand how Black Americas think about depression and help-seeking in the hopes of informing interventions to increase service use participation for those who feel that they might benefit.

\section{Methods}

A qualitative interviewing approach was used to explore the topic of depression, helpseeking, and service use with 17 Black American adults who had experienced depression. Following the protocol recommended by qualitative methodologist Charmaz (2006), indepth interviews were selected because they allowed the researcher to: 1) focus on the details and nuances of the participants' experiences, 2) explore various statements and/or topics in more depth, and 3) ask specifically about feelings, thoughts, perceptions, and behaviors. .Also, face-to-face interviews have been found to be preferable among African American research participants over telephone or mail surveys, allowing for trust between researcher and participant to be established, fostered, and respected (Burlew, 2003). Additionally, qualitative methods have been essential to health research in that it allows the researcher to capture the complexity of health experiences and behaviors (Stewart, Makwarimba, Barnfather, Letourneau, \& Neufeld, 2008).

\section{Recruitment and Interview Procedures}

This study was approved by the University of Michigan's Medical Institutional Review Board. Subsequent recruitment took place during the summer months of 2007 and 2008. Flyers containing information about the purpose of the study and the criteria for participation were posted at local colleges/universities, libraries, area churches, social service agencies, doctors' offices, and outpatient mental health organizations. Individuals meeting the following criteria were encouraged to contact the principal investigator: 1) aged 18 years or older, 2) identified as Black or African American, and 3) responded "yes" to at least one of the following: a) has felt sad, empty or depressed for 2 weeks or more during their life; $b$ ) has been told by a doctor, pastor, co-worker, family member or friend that they were depressed; or c) has seen a doctor, counselor or mental health professional for depression. While no incentive was offered during the 2007 recruitment period, an incentive of a $\$ 10$ gift card to a grocery or local discount store was offered during the 2008 recruitment period to encourage participation from a greater range of participants. The 2007 cohort included eight women, the majority of whom were pursuing graduate degrees. The 2008 cohort included five women and four men with various educational and occupational experiences. 
A total of 17 Black American men and women were ultimately recruited and provided informed consent. The principal investigator then scheduled and conducted semi-structured interviews with the participants in locations they selected, including their homes and local coffee shops. The interviews followed a guide created to capture the various aspects of the participants' experiences with depression, including help-seeking and service use experiences. The length of the interviews ranged from 30 minutes to 2.5 hours and were audio-recorded with the participants' permission. The interviews were transcribed by the principal investigator, a trained undergraduate research assistant, and a paid transcriptionist. Many of the "ums," "likes," and "you knows" were removed when appropriate to improve the clarity of the respondents' thoughts. Pseudonyms are used in the presentation of findings to ensure confidentiality.

\section{Analysis}

A thematic analysis was performed on the interview transcripts to identify relevant themes. This approach, as outlined by Braun and Clarke (2006), was selected because it allows the researcher to identify, refine, and report themes that emerge from the data, similar to the grounded theory approach developed by Glaser and Strauss (1967). However, the thematic analysis does not insist that the findings contribute heavily, or even remotely, to theory development as does grounded theory, which was not a goal of this study. The study aim was to explore the richness of the narratives shared and note overarching themes in the participants' experiences.

Several factors were considered when approaching the thematic analysis. As recommended by Braun and Clarke (2006), the author contemplated the following:

1) Will the analysis be a "rich description of the data set or a detailed account of one particular aspect?" (Braun \& Clarke, 2006, p. 11)

2) Will an inductive or deductive approach be used?

3) Is the level of analysis explicit or interpretive?

4) Is the researcher using an essentialist or a constructionist epistemology?

Even though a number of topics were discussed during these semi-structured interviews, the thematic analysis focused particularly on excerpts that highlighted the socio-cultural and historical context of the participants' experiences. The author approached the data inductively, allowing the themes to come from the data itself, not fitting the data into pre-set categories. In other words, the themes were not selected beforehand. The analysis was more interpretive in that the author sought "to identify or examine the underlying ideas, assumptions, and conceptualizations - and ideologies - that are theorized as shaping or informing the semantic content of the data" (Braun \& Clarke, 2006, p. 13). The author brought a constructivist orientation to this work, an epistemology that "does not seek to focus on motivation or individual psychologies, but instead seeks to theorize the socio-cultural context, and structural conditions, that enable the individual accounts that are provided" (Braun \& Clarke, 2006, p. 14). In other words, the researcher paid attention to the factors that externally pushed and pulled participants and not those that were internally or self-driven. 
After establishing the approach to examining the data, i.e., recorded experiences, the researcher progressed through the analysis in six phases as outlined by Braun and Clarke (2006): 1) familiarize yourself with your data, 2) generate initial codes, 3) search for themes, 4) review themes, 5) define and name themes, and 6) produce the report. First, the author became familiar with the data by reading and rereading the transcripts. No coding was completed at this point, but the investigator did jot down notes, including general thoughts about the data and what patterns and meanings seemed to be reflected. Braun and Clarke (2006) recommend this approach as it can help inform the formal coding process.

Next, the author generated some initial codes. The codes were quite simple at first, noting when keywords were used that reflected illness (e.g., "depression"), help-seeking behaviors (e.g. "talked to family member about depression," "talked to friend about depression"), or service use ("saw a therapist," "prescribed medication"). After the initial coding, the author began to search for themes. This process included recoding the data by (re)contextualizing the initial codes (i.e., providing some additional context). For example, as the author focused on excerpts coded as "beliefs," they were seen as providing context to respondents' illness, help-seeking, and service use experiences. These codes were reexamined and recoded to note various details about said belief (e.g., was this a belief held by the respondent; was it a belief thought to be held by Black Americans in general; what was the impact of the belief on the participants' experiences; what behaviors, practices, and subsequent beliefs were borne out of that belief, etc.). These recodes then became initial themes.

Braun and Clarke's (2006) fourth step calls for a review of the themes. Since this analysis aimed to highlight the socio-cultural and historical aspects of the participants' experiences with depression and help-seeking specifically, the investigator focused on those themes that seemed to speak to that particular context of the participants' experiences (e.g. "culturally-influenced belief that respondent believes shapes experience," "reference to the influence of slavery and civil rights on Black Americans beliefs about helpseeking"). After focusing on those specific themes, the author moved to what Braun and Clarke (2006) refer to as "define and refine" the selected themes, "identifying the "essence' of what each theme is about (as well as the themes overall), and determining what aspect of the data each theme captures" (p. 22). It was at this point that the investigator noticed that the themes seemed to speak or convey a message to the participants related to their depression and help-seeking experiences. The investigator then selected themes that reflected the voice that participants heard as they navigated their episodes of depression and attempts at help-seeking (e.g. "Black people don't get depressed," "Black people can deal with anything that comes their way").

Finally, the investigator wrote up the study's results. Noticing a clear pattern in how the themes broke down (i.e., the representation of the beliefs themselves and the impact of these beliefs on participants), the investigator decided to reflect this pattern in the presentation of the results, separating the findings into sections that reflected "the beliefs" and "their impact," each with their own subthemes. 


\section{Findings}

\section{The Respondents}

The 17 participants ranged in age from 21 to 57, with a mean age of 36 years (SD = 2.8; see Table 1). The majority of participants were female $(n=13)$. Over half of the participants $(n=9)$ were diagnosed with major depression at one point in their lives by a mental health professional, three were diagnosed by a medical physician, and 5 diagnosed themselves as having problems with depression. Overall, the study participants had achieved a high level of post-secondary education: five completed at least a Master's level education (three of whom were pursuing doctorates), four participants were college graduates, and four reported completing some college (three of whom were currently enrolled). Three participants reported their highest level of education completed as high school or receiving a GED, and one participant, the eldest in the study, did not graduate high school, finishing the $11^{\text {th }}$ grade.

Table 1. Profile of Study Respondents $(n=17)$

\begin{tabular}{|c|c|c|c|c|c|}
\hline Respondent & Gender & Age & Education & $\begin{array}{l}\text { Source of } \\
\text { Diagnosis }\end{array}$ & $\begin{array}{l}\text { Sought Professional } \\
\text { Help }\end{array}$ \\
\hline Carol & $\mathrm{F}$ & 24 & $\begin{array}{l}\text { Some } \\
\text { college* }\end{array}$ & Self & $\begin{array}{l}\text { Yes; talk therapy via } \\
\text { psychologist }\end{array}$ \\
\hline Denise & $\mathrm{F}$ & 26 & College** & Clinician & $\begin{array}{l}\text { Yes; talk therapy via } \\
\text { psychotherapist }\end{array}$ \\
\hline Derrick & M & 40 s*** & College & Clinician & $\begin{array}{l}\text { Yes; medication \& talk } \\
\text { therapy via various } \\
\text { mental health } \\
\text { professionals }\end{array}$ \\
\hline Devon & $\mathrm{F}$ & 32 & College & Self & No \\
\hline Donna & $\mathrm{F}$ & 37 & $\begin{array}{l}\text { High } \\
\text { School }\end{array}$ & Self & $\begin{array}{l}\text { No, not for depression but } \\
\text { did for other mental } \\
\text { health problems }\end{array}$ \\
\hline Doris & $\mathrm{F}$ & 57 & $\begin{array}{l}\text { Some High } \\
\text { School }\end{array}$ & Clinician & $\begin{array}{l}\text { Yes; medication via } \\
\text { unknown clinician }\end{array}$ \\
\hline Drucilla & $\mathrm{F}$ & 49 & $\begin{array}{l}\text { High } \\
\text { School }\end{array}$ & Clinician & $\begin{array}{l}\text { Yes; talk therapy via } \\
\text { counselor }\end{array}$ \\
\hline Elisa & $\mathrm{F}$ & 28 & $\begin{array}{l}\text { Master's } \\
\text { degree** }\end{array}$ & Clinician & $\begin{array}{l}\text { Yes; medication \& } \\
\text { therapy through } \\
\text { counselor; prescribing } \\
\text { clinician unknown }\end{array}$ \\
\hline Janelle & $\mathrm{F}$ & 27 & $\begin{array}{l}\text { Master's } \\
\text { degree }\end{array}$ & Self & No \\
\hline Kamille & $\mathrm{F}$ & 26 & $\begin{array}{l}\text { Master's } \\
\text { degree** }\end{array}$ & Clinician & $\begin{array}{l}\text { Yes; medication via } \\
\text { psychiatrist \& talk } \\
\text { therapy via psychologist }\end{array}$ \\
\hline Keith & M & 54 & College & Clinician & $\begin{array}{l}\text { Yes; medication only } \\
\text { through physician }\end{array}$ \\
\hline
\end{tabular}




\begin{tabular}{|c|c|c|c|c|c|}
\hline Respondent & Gender & Age & Education & $\begin{array}{l}\text { Source of } \\
\text { Diagnosis }\end{array}$ & $\begin{array}{l}\text { Sought Professional } \\
\text { Help }\end{array}$ \\
\hline Laura & $\mathrm{F}$ & 21 & $\begin{array}{l}\text { Some } \\
\text { college* }\end{array}$ & Clinician & $\begin{array}{l}\text { Yes; medication \& talk } \\
\text { therapy; professionals } \\
\text { unknown }\end{array}$ \\
\hline Margie & $\mathrm{F}$ & 49 & Doctorate & Clinician & $\begin{array}{l}\text { Yes; medication, talk } \\
\text { therapy, \& } \\
\text { hospitalization; } \\
\text { professionals unknown }\end{array}$ \\
\hline Miller & M & 43 & GED & Clinician & $\begin{array}{l}\text { Yes, medication only } \\
\text { through psychiatrist }\end{array}$ \\
\hline Richard & M & 39 & $\begin{array}{l}\text { Some } \\
\text { college }\end{array}$ & Clinician & $\begin{array}{l}\text { Yes; medication \& talk } \\
\text { therapy; professionals } \\
\text { unknown }\end{array}$ \\
\hline Shalesa & $\mathrm{F}$ & 35 & $\begin{array}{l}\text { Master's } \\
\text { degree** }\end{array}$ & Clinician & $\begin{array}{l}\text { Yes; medication via } \\
\text { psychiatrist } \& \text { talk } \\
\text { therapy via social worker }\end{array}$ \\
\hline Sidney & $\mathrm{F}$ & 28 & $\begin{array}{l}\text { Some } \\
\text { college* }\end{array}$ & Self & $\begin{array}{l}\text { Not for depression; } \\
\text { physician prescribed } \\
\text { medication for sleep } \\
\text { problems brought on by } \\
\text { "stress" }\end{array}$ \\
\hline
\end{tabular}

*Enrolled in college; **Enrolled in doctorate program; ***Not included in the mean

\section{Socio-Culturally and Historically-Shaped Beliefs}

Participants spent a fair amount of time speaking about how beliefs shaped by Black Americans' socio-cultural and historical experiences in the United States influenced their experiences with depression and help-seeking. Before speaking about how these beliefs influenced participants, it is important to first name those beliefs as the participants understood them.

\section{Black People Don't Get Depressed}

Many respondents talked about what Kamille, a 26-year-old woman, described as the "perception that Black folks don't get depressed." Sidney, a 28 -year-old woman, shared this sentiment stating that "some Black people believe that Black people can just dust their shoulders off and not get depressed and can deal with everything." Janelle, another woman in her late $20 \mathrm{~s}$, expanded on this idea, saying

I think [Black] people would joke around, "oh, Black people don't get depressed; they..." There was a saying. I can't remember, but it was pretty much saying Black people don't get depressed; they get over it or something to that effect, like it was non-existent in the Black community."

Other participants noted how this idea that depression was not something Blacks experienced was reflected in their families and communities, specifically. Twenty-eightyear-old Elisa stated that depression was a foreign topic within her family; rather, "white people talk about stuff like that." In her experience, depression was not seen as a "Black 
person's disease." Kamille shared this experience, stating that for her, therapy was something "for white people." For Laura, the youngest respondent at 21 years old, it was not even that depression was something experienced by others; it just did not exist. "At home, [she] kind of felt like there wasn't any such thing as depression. It wasn't real."

Janelle and Kamille felt that Black Americans' belief in the lack of depression among Black Americans was gender-specific and discussed depression in the context of being a Black woman. When talking about the messages she received about depression, Janelle said that for her, "the biggest thing was Black women are strong; they can handle anything." Kamille talked about this perception in greater detail:

I think that there is a perception that Black women don't get depression and that no matter what life throws at us, we just find a way to deal with it and overcome and pray and move on and then it's over, which is a really oversimplified version of what happens. So, I think that there's this perception that white women, they can cry and fall apart and they're depressed and they take their medications and whatever, but Black women aren't like that. (laughs) You know? We've been dealing with all kinds of adversities for generations. This a historical legacy that we just deal with it and move on, so I think that makes it hard to acknowledge the fact that you're depressed when you are.

Some participants viewed Black Americans' perception of depression as more complex. They believed that Black Americans did in fact have an understanding of depression but not one that necessarily reflected a clinical understanding of the illness. Elisa stated that distress in Black communities is "not seen as depression" and that "feel[ing] bad all the time" is "just how life is." She went on to say that there is an assumption that "people get depressed but you just suck it up. You deal with it." Sidney, Keith and Kamille made statements about the ability to deal with the difficulties of life by "dust[ing] your shoulders off" (Sidney), "walk[ing] it off” (Keith) or simply “just deal[ing] with it" (Kamille).

A number of respondents discussed a link between a shared historical past and the apparent rejection of the clinical conceptualization of depression. Participants shared the belief that life was supposed to be hard but nevertheless "dealt with" as a pervasive thought among Black Americans. They felt that it was the traversing of events in this "past" that, for many Black Americans, deemed one's seeming inability to cope as counter to the very definition of being Black. Respondents shared the belief that difficulties, including culturally-understood experiences of depression, could be successfully endured or surmounted. Elisa stated that based on "the context that Black Americans have had in this country, [Black Americans believed] you just had to struggle and suck it up. Depressed or not, [as a Black person] you had to suck it up and cope the best way you could." Elisa shared more about this "context," stating,

Well, I could always pull out slavery for one, but just... you know, discrimination, racism, poverty, economic strife, educational inequality, violence. I mean, these are all real reasons to be sad regardless if you're not predisposed to be depressed or not. So we've had to learn to cope with sadness whereas I think with my white and Asian friends, they didn't have to cope with that in the same way. 


\section{Black People Are Strong and Can Deal with Anything}

Perhaps the most prominent idea to emerge from these interviews was that participants thought that most Black Americans believed that Black Americans were a "strong people" who could deal with anything that came their way. Most of the respondents made some reference to the idea of "strength" being a definitive characteristic of being Black, with most connecting the idea of strength with the ability to deal with many hardships. It was a belief that Shalesa, a 35-year-old female, stated she had heard "so many times." Margie, a woman in her late 40s, described it more as a kind of "folk wisdom," "the kinda thing that, you know, when people are sittin' around the table bull shittin', that we all say, probably even me, you know."

Respondents felt that an air of pride often accompanied the belief that Blacks can deal with anything. Margie says that she had heard this belief and that "the Black American community say that with a lot of regard." A 24-year-old named Carol stated that as Black Americans, "we pride ourselves in being strong, emotionally strong and able to bear a lot." Some respondents stated how the idea of strength was firmly rooted in the historical and social experience of Black Americans in the United States. Denise, a woman in her mid20 s, stated that "[Blacks] feel like Black people are stronger than everybody else because Black people have been through so much." Keith, a 55-year-old male, stated it differently. When supporting his belief that Black Americans at large would agree with the idea that Blacks can deal with anything, he said, "I agree that they do. They deal with it. You know some of the comedians say, you know, they walk it off. And we've had to do it, you know? Collectively, we've had to do it."

Kamille had more to say about the historical legacy when asked to explain why she believed Black Americans experienced depression differently than other groups.

I think like we have such a historical cultural legacy of overcoming and dealing with things and being able to get through that I think that contributes to the perception that Black folks don't get depressed or even if you do, you just pray about it and God will take it away, and you just deal with it. Whereas I think that, for example, white people don't have that same type of legacy. I don't know, we always hear about celebrities going to like the hospital for like exhaustion and stuff. There's this perception that you're Black, you have to go out and work, you know? You don't have time to be going to the hospital talkin' 'bout you exhausted (laughs). You know, you just deal, and I think that's a huge difference.

Even those that did not explicitly link Black Americans' historical past to the theme of strength talked about the difficulties of the Black historical experience. When discussing how Blacks are different from other groups experiencing depression, Doris, the eldest respondent at 57 years old, believed that while depression does not discriminate, this country does: "Blacks are coming up from slavery, and we still have a lot of prejudiced people even today." She also believed that "Blacks have been exposed to a lot more hardships." Derrick, a male in his late 40s to early 50s, also cited Blacks' historical experience when explaining why he believed Blacks' experience of depression was different than other groups: 
Well because we had to fight, our backgrounds, our ancestors and where we came from and what we all had to go through. When you think about what Rosa Parks did that day on the bus, why does she have to sit in the back of the bus because of the color of her skin? That's depressing. And just thinking about what she stood for at that moment and we as a people had to fight for to be where we are today, to me that weighs more on a scale versus let's say a Caucasian race or Indians, the native Indians. You know what I'm saying? We had to fight more even though your particular situation or your particular family structure may be upper and you're doing well and you might not have to fight for nothing and your dad might be governor, you know? It's still there. Martin Luther King is still there. It's real, you know?

\section{The Impact}

After speaking about the socio-culturally and historically-shaped beliefs that they felt Black Americans held about concepts like depression and strength, the participants spent time discussing the impact these beliefs had on their personal experiences of depression and help-seeking. They spoke about how these types of beliefs initially shaped their thoughts about and experiences with depression, followed by a discussion around how they eventually began to challenge, for themselves, certain aspects of those culturally-held views.

\section{Initial (Mis)Understandings of Depression and Help-Seeking}

Some respondents expressed how these beliefs made it difficult for them to identify depression or recognize their symptoms as problematic. Kamille said that she "didn't even recognize [her] symptoms as depression...simply because [she] thought that... Black people just don't get depressed." Kamille went on to say,

I think I would be more willing to recognize a weepy white woman as being depressed versus a Black woman who did the same thing. I think there's almost a stereotype that that's how white people are, that they haven't had any hardships, so of course, they're gonna fall apart at the slightest provocation. I think I just thought that Black people just weren't...we just weren't built that way, so-tospeak."

Elisa stated how she "didn't think [depression] was an illness or anything until [she] got to be 19 and got out of [her] house and was around a bunch of white people" (laughs). She said that it was not until that time that she was "like ahh, wait! This isn't normal."

Other respondents cited the concept of strength in relation to Black Americans' historical past in the United States that made it difficult for them to admit to being depressed. Richard, a male aged 39, stated that the idea that "we are strong and when you are strong you can get over anything" made him reluctant to share his struggles with others for fear of appearing weak. He also stated that the historically and culturally-infused concept of strength kept him from seeking help: 
Because we have been through so much physically, it'll make you think that you don't need help. You are going to get over it one day; you just need the strength, you know?

Laura shared this sentiment stating:

I think because Black Americans have gone through so much as a race and have been through so many hard things that being depressed for what seems like no reason isn't something you can really admit to.

Janelle agreed:

Blacks will have [depression] but not acknowledge it or they'll deny it, especially Black women cause it's always "oh, you're the matriarch, you have to be the strong one" and you know, it's kinda like you're not allowed to be depressed, almost.

Eventual Rejection of the "Ability to Deal with Anything"

While there is understandably a great deal of pride surrounding the strength of a people who could endure being enslaved and the vestiges of the system of slavery including racism and discrimination, many respondents stated that as they begin to learn and understand more about depression, they began to take issue with some of the culturally-influenced beliefs. Of particular focus was the belief around the apparent ability to deal with just about anything. As Kamille shared:

I think there is a perception that we can deal with anything without any trouble, and that if we keep working at it then things will get better. But I honestly think that there is some things that happen...or maybe it's not even one single thing, it's a series of things... any one person should not be expected to just be able to deal with it on their own.

Elisa stated that even though she felt it was "reasonable" for many Black Americans to think that feeling bad was a part of life when "considering the context in which we've had in this country," she believes that it is "totally unreasonable to assume that [if] you feel bad, you're sad...that you just deal with it." Keith, who was quoted earlier discussing the ability of Blacks to "walk it off," quickly followed this statement saying that he did not mean to say that this was "always positive." Like Elisa and Keith, other respondents doubted the ability of anyone, including Blacks, to simply "deal with" struggles like depression. Margie stated:

It is frequently interpreted...that I don't need help, I can deal with anything that comes my way, and I not only strongly disagree with that for Black people, I strongly disagree with that for human beings in general.

Shalesa said it more plainly: "I don't think anyone can deal with anything that comes their way." She went on to say that "that whole image of the strong Black woman or the strong Black man can do more damage than good. It's not like Black people are invincible. No one is." 
Respondents also discussed the impact of simply accepting beliefs like "life sucks" and the ability to "suck it up and just deal with it" without reflecting on their impact on people and persons. Elisa observed that Black people come to accept that people feel bad and that life sucks without "realizing how it's affected how they look at life." Kamille also considered the acceptance of these beliefs and the toll it takes on Black Americans' mental health, many times unbeknownst to them:

I think it's really important that as Black people, we really stop and assess the emotional toll that things have on our lives. I think a lot of times we just sort of just suck it up and just deal with it without recognizing the emotional, the spiritual, the psychological toll that things can have on us. I mean, I think there's just been very bad situations that I've been in that I just thought that, I just have the strength to just deal with it and make it through without really assessing the emotional toll it was having on me.

\section{Discussion}

This study sought to highlight the socio-cultural and historical context of Black Americans' experiences with depression and help-seeking. The results helped illuminate the complexity of these experiences, especially when considering meanings and messages around what it means to be "Black" and what it means to be "depressed." The findings encourage us to think more critically and act with more intentionality when working with Black Americans around depression and help-seeking as well as other mental, behavioral, and public health issues. The findings were divided into two sections, "the beliefs" and "the impact," each with specific sub-themes. In the first section, cultural beliefs that respondents believed Black Americans held related to Black Americans' mental health experiences and racial identity were identified. Through the themes labeled as "Black people don't get depressed" and "Black people are strong and can deal with anything," respondents identified and discussed culturally-informed beliefs that seemed to equate the racial identity of "Black" with the concept of "strength." Respondents were particularly critical of the idea that Black people do not get depressed. While all of the respondents did not hold this belief at the time of the interview, they did discuss how they noticed what could be described as an ambiguity among Black Americans around what constitutes depression. Some indicated that many Black Americans simply did not "buy into" the idea of depression or thought it did not exist in Black communities. Still others felt that Black Americans understood the concept of depression but not in a way indicative of illness requiring medical intervention. These participants stated that depression, as Black Americans defined it, was simply a part of life that must be endured or pushed through, a finding that has been reflected in other research (Anderson et al., 2006; BeauboeufLafontant, 2007; Hines-Martin, Malone, Kim, \& Brown-Piper, 2003; Thompson, et al., 2004).

Infused in these beliefs were ideas related to strength and the ability to handle adversity due to Blacks' historical and socio-cultural past. Consistent with previous research, this study finds that strength and the ability to deal with adversity of many kinds is tied to the historical and social experiences of Blacks in the U.S. (Beauboeuf-Lafontant, 2007; USDHHS, 2001). Many respondents felt that the message they derived from these concepts 
was clear: if Black Americans could endure slavery as well as racism and discrimination as experienced during the Jim Crow era, they could and should be able to deal with anything. According to a few respondents, many Black Americans believed that it was because people from other races lacked this past that they were not "as strong" and were unable to deal with things. Thus, these non-Black Americans became depressed and needed help to cope. In conclusion, the message conveyed was that needing help to cope (with depression) was seen as something foreign to the Black experience.

The second section of findings, entitled "the impact," had sub-themes capturing how the aforementioned socio-culturally and historically-shaped beliefs impacted participants' depression experiences: "initial (mis)understandings of depression and help-seeking" and "eventual rejection of the "ability to deal with anything." These findings highlight the impact that the absence of conversations about mental health in Black communities can have on depression sufferers. Respondents felt that it was the relationship between Black identities and being strong that made depression seem non-existent in Black communities. This view of Black strengths also contributed to the racialized views of depression and help-seeking. Many respondents described the difficulty in trying to acknowledge and deal with their depression in communities that, for socio-cultural and historical reasons, viewed depression as undermining the image of Black strength and the act of seeking professional help was exclusive to "white people." For many of these participants, it was not until they left their familial homes or were exposed to people of other races that they begin to see depression as a "real" problem.

The idea that life was expected to be difficult and Black Americans were built to handle difficulties was also expressed by respondents. This understanding of life and living is supported by previous research showing that many Black Americans believe that hard times and adversity are a part of life and that they are expected to show strength in order to get through them (Anderson et al., 2006; Beauboeuf-Lafontant, 2007; Hines-Martin, et al., 2003; Thompson, et al., 2004). Some respondents echoed these sentiments stating that "feel[ing] bad all the time" was "not seen as depression" and instead, was "just how life is." Respondents perceived that Black Americans were to follow the lead of their ancestors and "dust your shoulders off," "walk it off," or simply "just deal with it."

Respondents believed that it was beliefs like these that delayed their attempts to seek help for their depression and currently keeps many Black Americans who need help from seeking it. They felt that the belief in their ancestors' ability to overcome adversity is understood too simply. While they believed that it was no doubt admirable and a source of great pride that Black Americans survived many historical and social atrocities, some respondents felt that the failure to recognize the "emotional, the spiritual, the psychological toll that things can have on us" makes the cry to "dust your shoulders off" an uninformed and potentially dangerous practice. For them, they felt that they had to go through a process of rejecting such beliefs in order to pursue the help that eventually and, for some, successfully addressed their depression. 


\section{Implications for Research and Practice}

While this study was not without its limitations, including the reliance on selfdiagnosis in some participants and drawing heavily from one particular demographic of the Black American population, it showed how beliefs around being "Black" and "depressed" impacted how respondents thought about themselves and help-seeking for their depression. The study uncovered the perception that Black Americans suffering from depression might have to go through a process of rejecting or, perhaps better articulated as, reconciling being depressed with certain aspects of their cultural/racial identity in order to seek help for depression. Future research is needed to investigate this idea more explicitly, intentionally focusing on the role of identity in Black Americans' illness experiences and the process of identity rejection and/or reconciliation. While culturally adapted interventions do exist that appreciate and target illness education, healthy coping, and stigma bred by culturallyshaped beliefs (Ward \& Brown, 2015), studies need to focus more explicitly on how identities around race, ethnicity, and gender interact with those around illness, as well as the process of identity rejection and/or reconciliation and their role in facilitating treatment engagement.

This study included the views of participants who had not sought a formal diagnosis of depression. The idea was to capture the thoughts from Black Americans who do not, for a variety of reasons, seek professional help for depression. While this study offers a glimpse into the perspectives of non-professionally-diagnosed individuals who are often missing from the research, the findings might have been strengthened by capturing how those participants identified themselves as depressed. In other words, a discussion around how these individuals determined they had experienced depression would help us better understand the similarities and differences in professionals' and lay individuals' understanding of depression.

Future research could also explore the experiences of a more diverse group of Black Americans. Most of the participants in this study had completed a high level of education, and while the findings were fairly consistent across education levels, further study would continue to seek and note within group differences.

Social work practitioners can benefit from a more nuanced understanding of the sociocultural and historical context of the clients they serve. Understanding that Black Americans may go through a process in which they must contemplate how depression impacts their racial, and possibly core, identity can help social workers be more culturallyresponsive to these clients. Clients who struggle to come to terms with certain aspects of diagnosis and treatment would then be seen as engaging in a more complex process of "accepting" their illness rather than being labeled as resistant, non-adherent, or noncompliant. Practitioners could then aid clients in this process, or at least provide the opportunity to attend to this process, as part of their therapeutic work and/or interventions. Engaging in this process not only expands upon social work's tenets of seeing the person in environment (i.e., context) but also operate from a strengths-based perspective in that they see the processing around identity in a less problematic light. 


\section{Conclusion}

It is important that research continues to take a more culturally-focused approach to better understanding Black Americans' ideas about depression, help-seeking, and treatment with the goal of informing the design and implementation of interventions aimed at improving the rates of mental health service use rates and the experiences of those who feel they may benefit from services. This focus on being culturally-attentive and responsive in research and practice will also help destigmatize depression and treatment as well as redefine the concept of "strength," thereby shifting the understanding of depression, treatment and what it means to be a Black American and experience a mental health problem.

\section{References}

Alang, S. M. (2016). "Black folk don't get no severe depression": Meanings and expressions of depression in a predominantly black urban neighborhood in Midwestern United States. Social Science \& Medicine, 157, 1-8. doi: https://doi.org/10.1016/j.socscimed.2016.03.032

Alegría, M., Chatterji, P., Wells, K., Cao, Z., Chen, C., Takeuchi, D., Jackson, J., \& Meng, X. (2008). Disparity in depression treatment among racial and ethnic minority populations in the United States. Psychiatric Services, 59(11), 1264-1272. doi: https://doi.org/10.1176/ps.2008.59.11.1264

Alegría, M., Lin, J. Chen, C., Duan, N., Cook, B., \& Meng, X. (2012). The impact of insurance coverage in diminishing racial and ethnic disparities in behavioral health services. Health Services Research, 47(3 Pt 2), 1322-1344. doi: https://doi.org/10.1111/j.1475-6773.2012.01403.x

Anderson, C. M., Robins, C. S., Greeno, C. G., Cahalane, H., Copeland, V. C., \& Andrews, R. M. (2006). Why lower income mothers do not engage with the formal mental health care system: Perceived barriers to care. Qualitative Health Research, 16(7), 926-943. doi: https://doi.org/10.1177/1049732306289224

Angel, R., \& Thoits, P. (1987). The impact of culture on the cognitive structure of illness. Culture, Medicine \& Psychiatry, 11(4), 465-494. doi: https://doi.org/10.1007/BF00048494

Bagley, S. P., Angel, R., Dilworth-Anderson, P., Liu, W., \& Schinke, S. (1995). Panel V: Adaptive health behavior among ethnic minorities. Health Psychology, 14(7), 632640. doi: https://doi.org/10.1037/0278-6133.14.7.632

Beauboeuf-Lafontant, T. (2007). "You have to show strength": An exploration of gender, race, and depression. Gender \& Society, 21(1), 28-51. doi: https://doi.org/10.1177/0891243206294108

Braun, V., \& Clarke, V. (2006). Using thematic analysis in psychology. Qualitative Research in Psychology, 3(2), 1-41. doi: https://doi.org/10.1191/1478088706qp063oa

Broman, C. (1987). Race differences in professional help seeking. American Journal of Community Psychology, 15, 473-489. doi: https://doi.org/10.1007/BF00915215 
Burlew, A. K. (2003). Research with ethnic minorities: Conceptual, methodological, and analytical issues. In G. Bernal, J. E. Trimble, A. K. Burlew, \& F. T. L. Leong (Eds.), Handbook of racial \& ethnic minority psychology (pp. 179-197). Thousand Oaks, CA: Sage.

Capers, C. F. (1991). Nurses' and lay African Americans' beliefs about behavior. Western Journal of Nursing Research, 13(1), 123-135. doi: https://doi.org/10.1177/019394599101300109

Charmaz, K. (2006). Constructing grounded theory: A practical guide through qualitative analysis. Thousand Oaks, CA: Sage.

Fabrega, H., Jr. (1989). Cultural relativism and psychiatric illness. The Journal of Nervous and Mental Disease, 177(7), 415-425. doi: https://doi.org/10.1097/00005053-198907000-00005

Glaser, B. G., \& Strauss, A. L. (1967). The discovery of grounded theory: Strategies for qualitative research. Chicago: Aldine.

Good, B. J. (1997). Studying mental illness in context: Local, global or universal? Ethos, 25(2), 230-248. doi: https://doi.org/10.1525/eth.1997.25.2.230

Hines-Martin, V., Malone, M., Kim, S., \& Brown-Piper, A. (2003). Barriers to mental health care access in a Black American population. Issues in Mental Health Nursing, 24, 237-256. doi: https://doi.org/10.1080/01612840305281

Kessler, R. C., Berglund, P., Demler, O., Jin, R., Merikangas, K. R., \& Walters, E. E. (2005). Lifetime prevalence and age-of-onset distributions of DSM-IV disorders in the National Comorbidity Survey Replication. Archives of General Psychiatry, 62, 593-602. doi: https://doi.org/10.1001/archpsyc.62.6.593

Kessler, R. C., Chiu, W. T., Demler, O., \& Walters, E. E. (2005). Prevalence, severity, and comorbidity of 12-month DSM-IV disorders in the National Comorbidity Survey Replication. Archives of General Psychiatry, 62, 617-627. doi: https://doi.org/10.1001/archpsyc.62.6.617

Keyes, K. M., Hatzenbuehler, M. L., Alberti, P., Narrow, W. E., Grant, B. F., \& Hasin, D. S. (2008). Service utilization differences for Axis I psychiatric and substance use disorders between White and Black adults. Psychiatric Services, 59, 893-901. doi: https://doi.org/10.1176/ps.2008.59.8.893

Kleinman, A. (1980). Major conceptual and research issues for cultural (anthropological) psychiatry. Culture, Medicine and Psychiatry, 4(1), 3-13. doi: https://doi.org/10.1007/BF00051939

Kleinman, A. (1988). Rethinking psychiatry: From cultural category to personal experiences. Free Press: New York.

Kleinman, A. (1992). Local worlds of suffering: An interpersonal focus for ethnographies of illness experience. Qualitative Health Research, 2(2), 127-134. doi: https://doi.org/10.1177/104973239200200202 
Lopez, S. R., \& Guarnaccia, P. J. J. (2000). Cultural psychopathology: Uncovering the social world of mental illness. Annual Review of Psychology, 51, 571-598. doi: https://doi.org/10.1146/annurev.psych.51.1.571

Matthews, A. K., \& Hughes, T. L. (2001). Mental health service use by Black American women: Exploration of subpopulation differences. Cultural Diversity and Ethnic Minority Psychology, 7(1), 75-87. doi: https://doi.org/10.1037/1099-9809.7.1.75

Murray, C. B. (2001). Culture as a determinant of mental health. In N. J. Smelser \& P. B. Baltes (Eds.), International encyclopedia of the social and behavioral sciences (pp. 3143-3147). Amsterdam: Pergamon. doi: https://doi.org/10.1016/B0-08-0430767/03837-7

Olafsdottir, S., \& Pescosolido, B. A. (2009). Drawing the line: The cultural cartography of utilization recommendations for mental health problems. Journal of Health and Social Behavior, 50, 228-244. doi: https://doi.org/10.1177/002214650905000208

Redmond, M. L., Galea, S., \& Delva, J. (2009). Examining racial/ethnic minority treatment experiences with specialty behavioral health service providers. Community Mental Health Journal, 45, 85-96. doi: https://doi.org/10.1007/s10597-008-9164-5

Rostain, A. L., Ramsay, J. R., \& Waite, R. (2015). Cultural background and barriers to mental health care for African American adults. Journal of Clinical Psychiatry, 76(3), 279-283. doi: https://doi.org/10.4088/JCP.13008co5c

Scheff, T. (1966). Being mentally Ill: A sociological theory. Chicago: Aldine.

Schnittker, J., Freese, J., \& Powell, B. (2000). Nature, nurture, neither, nor: Black-White differences in beliefs about the causes and appropriate treatment of mental illness. Social Forces, 78(3), 1101-1132. doi: https://doi.org/10.1093/sf/78.3.1101

Small, M. L., Harding, D. J, \& Lamont, M. (2010). Reconsidering culture and poverty. The Annals of the American Academy of Political and Social Science, 629(1), 6-27. doi: https://doi.org/10.1177/0002716210362077

Stewart, M., Makwarimba, E., Barnfather, A., Letourneau, N., \& Neufeld, A. (2008). Researching reducing health disparities: Mixed methods approaches. Social Science \& Medicine, 66, 1406-1417. doi: https://doi.org/10.1016/j.socscimed.2007.11.021

Thompson, V. L. S., Bazile, A., \& Akbar, M. (2004). Black Americans' perceptions of psychotherapy and psychotherapists. Professional Psychology: Research and Practice, 35(1), 19-26. doi: https://doi.org/10.1037/0735-7028.35.1.19

U. S. Department of Health and Human Services [USDHHS]. (1999). Mental health: A report of the Surgeon General. Rockville, MD: National Institute of Mental Health. Retrieved from https://profiles.nlm.nih.gov/ps/access/NNBBHS.pdf

USDHHS. (2001). Mental health: Culture race and ethnicity-a supplement to mental health: A report of the surgeon general. Rockville, MD: US Department of Health and Human Services, Public Health Service, Office of the Surgeon General. Retrieved from http://health-equity.lib.umd.edu/866/1/sma-01-3613.pdf 
Wang, P. S., Lane, M., Olfson, M., Pincus, H. A., Wells, K. B., \& Kessler, R. C. (2005). Twelve-month use of mental health services in the United States: Results from the National Comorbidity Survey Replication. Archives of General Psychiatry, 62(6), 629-640. doi: https://doi.org/10.1001/archpsyc.62.6.629

Ward, E. C., \& Brown, R. L. (2015). A culturally adapted depression intervention for African American adults experiencing depression: Oh Happy Day. American Journal of Orthopsychiatry, 85(1), 11-22. doi: https://doi.org/10.1037/ort0000027

Williams, D. R., Gonzalez, H. M., Neighbors, H., Neese, R., Abelson, J. M., Sweetman, J., \& Jackson, J. S. (2007). Prevalence and distribution of major depressive disorder in Black Americans, Caribbean Blacks, and Non-Hispanic Whites: Results from the National Survey of American Life. Archives of General Psychiatry, 64(3), 305-315. doi: https://doi.org/10.1001/archpsyc.64.3.305

Author note: Address correspondence to: Rosalyn Denise Campbell, PhD, LMSW, School of Social Work, University of Georgia, 279 Williams St., Athens, GA 306051746.rdcampb@uga.edu. 